\title{
O PAC e a economia paranaense
}

\author{
Marcio José V argas da Crus* \\ Luciano Nakabashi*
}

\section{Introdução}

O Programa de Aceleração do Crescimento - PAC (2007-2010), apresentado recentemente pelo governo federal, é uma iniciativa com grande potencial dentro da perspectiva de melhora no planejamento econômico, que há anos não encontra espaço na agenda brasileira. Nele existem propostas e estabelecimentos de algumas prioridades, com destaque para investimentos em infra-estrutura, ainda que deixe a desejar no que se refere ao próprio processo de planejamento da alocação de recursos públicos. Além disso, falta uma maior audácia quanto à condução da política fiscal, destacando-se a redução dos gastos correntes e uma sintonia mais fina desta com a condução das políticas monetária e cambial.

De qualquer forma, o ponto fundamental em torno destas propostas são as ações, ou seja, o que de fato será realizado e a continuidade deste processo, buscando esclarecer o caminho a ser percorrido para um cenário de prosperidade econômica no longo prazo.

Primeiramente, cabe ressaltar que as medidas propostas pelo PAC, estão organizadas em cinco blocos:

1. Investimento em Infra-Estrutura

2. Melhora do Ambiente de Investimento

3. Medidas Fiscais de Longo Prazo

4. Desoneração e Aperfeiçoamento do Sistema Tributário

5. Estímulo ao Crédito e ao Financiamento

Diante deste cenário, uma questão importante a se levantar é: o que se esperar do PAC com relação à economia paranaense? Referindo-se às propostas do programa, os investimentos em infra-estrutura são os que se apresentam uma maior definição quanto ao âmbito regional. A seguir, algumas informações a respeito do PAC e as iniciativas inicialmente projetadas são apresentadas.

\footnotetext{
* Mestre em Economia pela Universidade Federal do Paraná. Professor do Departamento de Economia da Universidade Federal do Paraná (UFPR) - marciocruz@ufpr.br

** Doutor em Economia pelo CEDEPLAR/UFMG. Professor do Departamento de Economia da Universidade Federal do Paraná (UFPR) - luciano.nakabashi@ufpr.br.
} 
Quadro 1. Previsão de Investimento Regional em Infra-estrutura 2007-2010

\begin{tabular}{lrcrr}
\hline Região & Logística & Social e Urbana & Total & Participação (\%) \\
\hline Norte & 6.3 & 11.9 & 50.9 & 10.10 \\
Nordeste & 7.4 & 43.7 & 80.4 & 15.96 \\
Sudeste & 7.9 & 41.8 & 130.5 & 25.90 \\
Sul & 4.5 & 14.3 & 37.5 & 7.44 \\
Centro-Oeste & 3.8 & 8.7 & 24.1 & 4.78 \\
Nacional * & 28.4 & 50.4 & 180.5 & 35.82 \\
TOTAL & 58.3 & 170.8 & 503.9 & 100.00 \\
\hline
\end{tabular}

Fonte: Ministério do Planejamento, 2007

Iniciando pela previsão de investimentos em infra-estrutura, de acordo como quadro 1 , estes valores são representativos? Considerando o PIB brasileiro de 2005, em valores correntes, o montante de investimentos representa aproximadamente $26 \%$ daquele. Assim, esses investimentos representam uma média de 6,5\% do PIB ao ano. Diante do fato de que, em média, o governo brasileiro tem investido o equivalente a aproximadamente $2,2 \%$ do PIB ao ano na última década (Gráfico 1), trata-se de uma melhora expressiva no montante de investimentos.

\section{Gráfico 1. Investimento da administração pública (\% PIB) - Contas Nacionais}

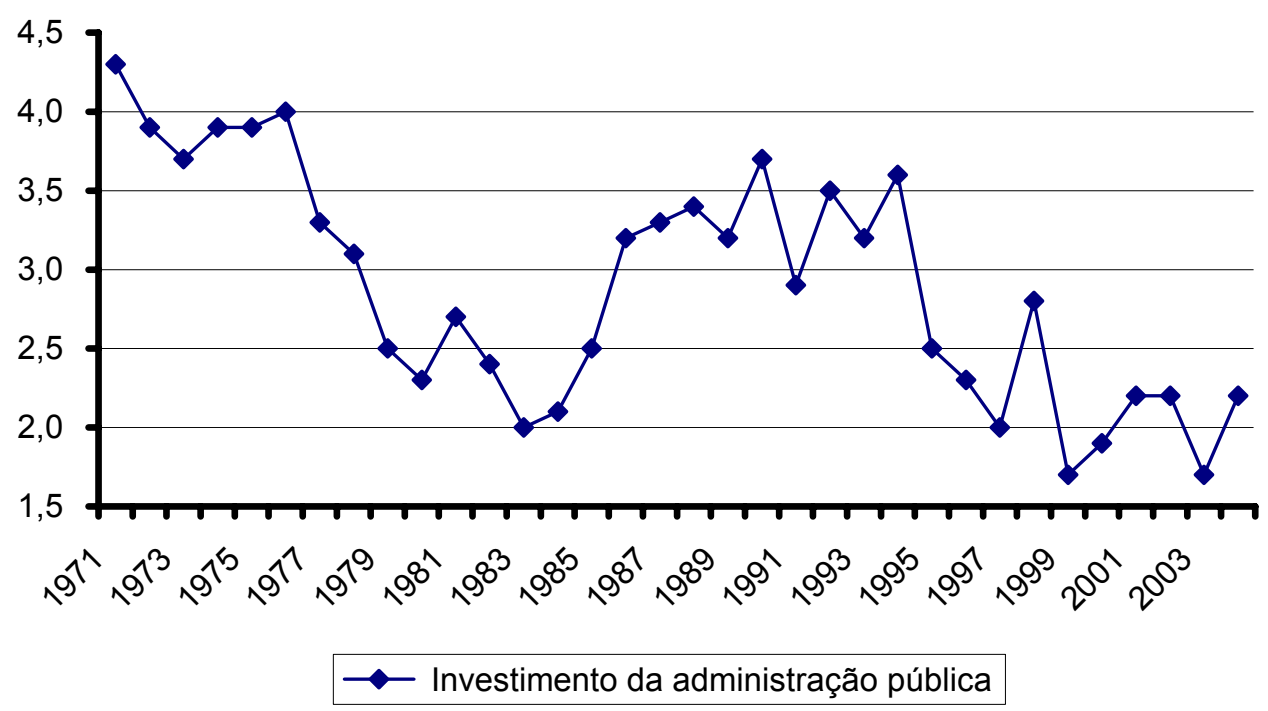

Fonte: IBGE, apud, Giambiagi (2005)

Contudo, cabe ressaltar que a origem dos recursos não está concentrada apenas no governo. As parcerias público-privada têm um importante papel na geração dos novos investimentos previstos pelo governo federal. Assim, o sucesso do PAC depende parcialmente de investimentos incertos. De acordo com informações fornecidas pelo 
Ministério do Planejamento (2006), apenas R \$ 67,8 bilhões provêm do orçamento do governo central.

No que diz respeito ao Paraná os investimentos até 2010, em infra-estrutura logística e energética na Região Sul, prevêem:

a) Concessão da BR 116 Curitiba - Divisa SC/RS e Curitiba - SP e Concessão dos trechos BR 116 - 376 - 101 : Curitiba - Florianópolis

b) Adequação do contorno Leste de Curitiba (BR 116)

c) Ampliação da capacidade do corredor ferroviário do oeste do Paraná

d) Construção e recuperação de berços do Porto de Paranaguá

e) Ampliação da pista de pouso e terminal de cargas do aeroporto Afonso Pena (em mais $5.000 \mathrm{~m}^{2}$ )

f) Construção da segunda ponte internacional sobre o Rio Paraná em Foz do Iguaçu

g) Implantação da Usina Hidrelétrica (UHE) Mauá no Rio Tibagi

h) Prevista implantação das UHE'S: São Roque - Rio Canoas - Potência: 214 MW; Baixo Iguaçu - Rio Iguaçu - Potência: 340 MW; Itapiranga - Rio Uruguai - Potência: 580 MW; 4 -(?) 482 MW; e da Usina Termelétrica (UTE) Carvão - 350 MW (Indicativo)

i) Linhas de transmissão (LT): LT Londrina - Maringá - PR; LT Itararé Jaguariaíva - SP- PR; LT Curitiba - Bateias - PR; LT Bateias - Joinville Norte - PR-SC; LT Cascavel Oeste - Foz do Iguaçu Norte - PR

j) Implantação de um Poliduto, ligando Cuiabá - MT a Paranaguá - PR, passando por Araucária, onde está instalada a REPAR e que poderá escoar parte da produção de álcool do Estado.

Quanto à infra-estrutura social e urbana, de acordo com a proposta, o Paraná será beneficiado em ações relativas a saneamento, habitação e a ampliação do Programa Luz para Todos, que já estava em andamento, visando a universalização do acesso e uso da energia elétrica.

Estas propostas respondem adequadamente às necessidades referentes à infraestrutura no Paraná, respeitando a ordem de prioridade? Além disso, qual a magnitude das mesmas, frente a demanda por investimentos em infra-estrutura? Essas questões são bastante complexas. Primeiramente, ainda não há um método comum utilizado pelas Unidades Federativas para elaborar este tipo de levantamento, o que, de certa forma, representa um atraso quanto ao processo de planejamento e decisão na alocação de recursos públicos. 
De acordo com a Federação da Indústria do Paraná - FIEP, o Programa de Aceleração de Crescimento (PAC) irá contemplar 29\% da demanda de investimentos em infra-estrutura no estado do Paraná. Já a Organização das Cooperativas do Estado do Paraná - OCEPAR, apontam que as inversões do PAC no Paraná representariam cerca de 15,0\% das carências infra-estruturais identificadas (Lourenço, 2007). Porém, cabe lembrar que o PAC não se restringe a investimentos em infra-estrutura.

A Associação dos Municípios do Paraná - AMP, em um estudo preliminar realizado pelo Instituto Brasileiro de Administração Municipal - IBAM, aponta que os municípios paranaenses terão perdas de aproximadamente $\mathrm{R} \$ 101,187$ milhões com o PAC em 2007. De acordo com AMP (2007), o valor refere-se, basicamente, à perda com o Imposto de Renda (IR) e o Imposto sobre produtos Industrializados (IPI) - as duas principais fontes de receita do Fundo de Participação dos Municípios (FPM).

O que diz o governo do estado do Paraná? Alguns governadores inicialmente criticaram a apresentação do PAC, alegando o fato de que não teriam sido devidamente consultados. Essa posição foi defendida principalmente por governadores de partidos de oposição ao governo federal. Porém, o governo do estado, posicionou-se em defesa das propostas apresentadas pelo PAC, alegando a necessidade de sua implementação com urgência, ainda que reconheça o fato de que o programa não contempla todas as demandas no âmbito em que se propõe (Agência Estadual de Notícias, 2007).

Contudo, mesmo diante de manifestações de diversas forças políticas, chama a atenção que, apesar de ressaltarem a necessidade de ampliação dos investimentos em infraestrutura para o estado, vistos como insuficientes, não parece haver grandes divergências referentes à relevância das propostas apresentadas inicialmente. Provavelmente, o fato das propostas mais detalhadas se referirem a obras amplas de infra-estrutura e estarem razoavelmente distribuídas geograficamente entre os principais pólos econômicos do Estado, explique esta reação.

Além disso, as ações estão voltadas para alguns gargalos já conhecidos da população paranaense como, por exemplo, a necessidade de investimentos no Porto de Paranaguá, a ampliação dos aeroportos para o transporte de carga, os investimentos em estradas e a implantação do poliduto, que pode representar a ampliação de boas oportunidades para o setor de energias renováveis. Porém, não está clara a origem dos recursos necessários para colocar em marcha as ações propostas para o estado, o que, neste momento, trata-se de um importante desafio ao governo. 
Um ponto positivo a respeito do PAC, que a princípio se caracteriza como uma carta de intenções de investimento com a qual o governo federal se compromete, trata-se da transparência quanto ao compromisso de alocação de recursos públicos. Isto pode favorecer o processo de monitoramento e cobrança dos resultados por parte da sociedade.

Com relação aos impactos na economia paranaense, um maior detalhamento da proposta referente aos investimentos em infra-estrutura, incorporando o cronograma econômico-financeiro das obras e a origem dos recursos, poderá colaborar para uma análise mais cuidadosa. Quanto a desoneração tributária, observa-se que a estrutura produtiva do Paraná tende a não ser muito beneficiada com os setores favorecidos, uma vez que são apresentadas algumas propostas de caráter vertical. Já as medidas fiscais de longo prazo, a melhoria do ambiente de investimento e o estímulo ao crédito e ao financiamento, são mais horizontais, beneficiando os estados de forma agregada.

De qualquer forma, o sucesso da implementação do PAC supõe uma reação por parte da iniciativa privada, do setor produtivo de forma geral. Caso contrário, tais medidas não terão impactos relevantes sobre o crescimento econômico.

Novamente, retomamos a necessidade de uma melhor articulação na condução das políticas monetária e fiscal. A economia paranaense, assim como os demais estados da nação, necessita de um cenário favorável quanto às expectativas de retorno do capital, investidos no setor produtivo, para que de fato, estes investimentos possam se concretizar.

\section{Referências Bibliográficas}

Associação dos Municípios do Paraná (2007). Paraná deixa de ganhar R\$ 101 milhões com PAC: prefeitos pedem compensação ao governo federal. Disponível em www.ampr.org.br, capturado em 5 de março de 2007.

GIAMBIAGI, F. (2006). A política fiscal do governo Lula em perspectiva histórica: qual é o limite para o aumento do gasto público? Texto de discussão, 1169, IPEA: Brasília, março.

MINISTÉRIO DO PLANEJAMENTO. Programa de Aceleração do Crescimento - 20072010 (material para a imprensa). Disponível em www.planejamento.gov.br, capturado em 15 de fevereiro de 2007.

FIEP (2007). Fiep entrega demandas das indústrias do sul a ministros. Disponível em www.fiepr.org.br, capturado em 5 de março de 2007.

LOURENÇO,G, M.(2007). O PAC e a infra-estrutura do Paraná. Gazeta do Povo, Curitiba, 12 , fev.

AGÊNCIA ESTADUAL DE NOTÍCIAS. Requião defende aprovação do PAC. Disponível em www.aenoticias.pr.gov.br, capturado em 6 de março de 2007. 
